\title{
On Deep Learning-Based Synthesis of Language Training and Humanistic Education in College English Teaching
}

\author{
Fang Gu \\ Department of College English, Zhejiang Yuexiu University, Shaoxing, China \\ Email:26536978@qq.com
}

How to cite this paper: Gu, F. (2021) On Deep Learning-Based Synthesis of Language Training and Humanistic Education in College English Teaching. Open Access Library Journal, 8: e7493.

https://doi.org/10.4236/oalib.1107493

Received: May 6, 2021

Accepted: June 20, 2021

Published: June 23, 2021

Copyright $\odot 2021$ by author(s) and Open Access Library Inc.

This work is licensed under the Creative Commons Attribution International License (CC BY 4.0).

http://creativecommons.org/licenses/by/4.0/

\section{(c) (i) Open Access}

\begin{abstract}
In recent years, the overemphasis on language training and the overlook of humanistic education in English teaching arouse a shared concern among scholars. Correspondingly, a new reform has been initiated, calling for returning English teaching to the place as a discipline of humanities. More and more scholars tend to believe that strengthening humanistic education and enhancing language skills are not mutually exclusive in the discipline of English, which, in contrast, should be synthesized. Under the guidance of Deep Learning Theory and Deeper Learning Cycle (DELC), considering the course features, the current paper explores a deep learning path of implementing the model of language teaching combined with humanistic education through the following steps: problem solving-based objective setting, two-way exploration of materials related to humanistic education, and deep learning-based integration of humanistic education into learning process, hoping to provide a reference for the design, construction and implementation of humanistic education in language courses.
\end{abstract}

\section{Subject Areas}

Language Education

\section{Keywords}

College English, Humanistic Education, Deep Learning, Deeper Learning Cycle

\section{Introduction}

The acceleration of globalization has pushed foreign language education to a new height, which is of great and far-reaching significance to the development of 
individuals, the society and the country. Foreign language teaching is an important part of higher education, of which college English teaching plays an irreplaceable role in talent training of college students. However, under the current course syllabus, college English tends to emphasize on "training" rather than "educating", "utility" rather than "humanity", which has aroused a shared concern among scholars (Zhang Zhongzai, 2003) [1].

The tendency to dilute humanistic education caused by the transformation of teaching objectives was a fatal injury to foreign language teaching. Under the guidance of utilitarianism, the humanistic education was fading, which directly resulted in the decline of students' humanistic spirit. Liu Yi (2000) pointed out that students majoring in foreign languages have a big gap with other liberal arts students in terms of depth in thought, structure of knowledge and analyzing ability, which was caused by the fact that foreign language teaching pays too much attention to language skill training [2]. After four years of professional study, many students had an excellent pronunciation and fluent spoken language, but they were lack of deep thinking ability, and suffered from logic confusion in expression, poor organization and inadequate critical thinking (Liu Xiaomin, 2013) [3]. The curriculum of foreign language courses had neglected the contents of humanistic education, which led to the shallow cultural accomplishment for students, and it was also difficult for them to undertake cross-cultural communication (Ren Xiujuan, 2009) [4]. Therefore, Hu Wenzhong and Sun Youzhong (2006) put forward that when training foreign language talents, we should not only consider the market demand, but also the fundamental goal of higher education [5]. In order to strengthen humanistic education, it was necessary to reform the existing teaching model.

As is accepted that improving humanistic quality of college students is the call of the times, it leads a direction for the current university education reform (Luo Hexiang, 2008) [6], which also arouses the call of strengthening humanistic education in college English teaching, and then more teaching practices are following. Academia practically discusses the way of humanistic education in college English teaching, most of which are the personal experience of teachers, lacking the guidance of systematic theories (Luo Hexiang, 2008 [6]; Yue Hongxing, 2010 [7]; Sun Lu, 2018 [8]). Thus, research on humanistic education in college English under the guidance of systematic theories is comparatively scarce, of which the breadth and depth need to be further extended as well. Therefore, the current paper constructs a college English teaching model aiming to carry out humanistic education through language training by the guidance of Deep Learning Theory and Deeper Learning Cycle, an innovation of humanistic education-oriented college English teaching practice.

\section{Humanistic Education}

The term, humanistic education, frequently used in the educational theory research circle, is a popular term with different versions of interpretations, which 
may result in either confusion in theory or misleading in practice. Therefore, a brief introduction to the related concept of humanistic education, as well as its characteristics is of great necessity.

\subsection{Connotation of Humanistic Education}

In today's educational theories, different scholars hold different viewpoints toward humanistic education based on their personal understanding. Some pointed out that humanistic education meant the education of humanities, namely, education in literature, history, philosophy, language and arts (Zhang Meng, 2008 [9]; Cai Jigang, 2017 [10]). Others also believed that it involved comprehensive physical and mental training, especially the cultivation of human nature, or the enlightenment of human beings. The so-called humanistic education was "human education" (Ren Xiujuan, 2009 [4]; Sun Youzhong, 2015 [11]).

To sum up, the above views of humanistic education emphasize two meanings: First, humanistic education starts from humanistic knowledge education, such as literature, history, philosophy, language and arts, which are important carriers of humanistic education. Second, the core of the humanistic education is about the education of humanistic spirit. Humanistic education does not only mean that students can learn a few more liberal arts courses, know more humanistic knowledge, or even become a "living encyclopedia", but to cultivate them with human nature, personality and humanistic spirit.

\subsection{Characteristics of Humanistic Education}

Humanistic education takes cultivating humanistic spirit as its core and focuses on personality shaping. Humanistic education is not only a kind of education defined from the content level, but also an educational value orientation that should be permeated into the whole education process. In humanistic education, the excellent cultural achievements of human beings are taught and then internalized into students' personality, mental capacity and temperament through knowledge transfer, environmental edification and students' personal practice, with the ultimate meaning of enhancing students' humanistic spirit.

The Ministry of Education's 2020 latest edition of College English Curriculum Requirements puts forward that "College English course is a part of the humanistic education in universities, which has the dual attributes of instrumentality and humanism" [12]. The Requirements brings college English curriculum into the framework of humanistic education, which not only clarifies its subject attributes, but also indicates that it should be carried out under the guidance of humanistic education. The Requirements further points out that "the core of humanism is to put students first, to carry forward students' value, to pay attention to the cultivation and all-round development of students" [12]. This description is fundamentally consistent with academic understanding of humanistic education.

To be precise, to insist on the humanity in college English course is to stick to 
establishing the teaching objectives and requirements, arranging college English curriculum and teaching materials, and organizing teaching process, evaluation and reflection under the concept of humanistic education. It requires the change of teaching paradigm, indicating the direction for a new round of college English teaching reform.

\section{Connotation of Deep Learning and Deeper Learning Cycle}

\subsection{Deep Learning Theory}

Scholars Ference Marton and Roger Saljo (1976) were the first to put forward the term "deep learning" in their paper On Qualitative Difference in Learning. Outcome and Process [13]. They first proposed the concepts of surface learning and deep learning in an experiment on reading ability. Deep learning focuses on catching the idea and academic connotation of the article. After that, other scholars continued to develop it (Ramsden, 1988 [14]; Entwistle, 1997 [15]; Biggs, 1982 [16]). Huberman (2014) pointed out that deep learning was a deep understanding of knowledge and application of the understanding ability to solve real problems [17]. American Research Institute (2015) also proposed that deep learning was the process of students' deep understanding of knowledge and application of this ability to solve problems in real situations [18]. Deep learning occurred on the basis of understanding, which, according to Bloom's taxonomy, extended to explanation, meaning interpretation, transfer and application, opinion formation, empathy and self-knowledge (Wiggins \& McTighe, 1998) [19]. Domestic scholars' research on deep learning started relatively late. He Ling and Li Jiahou (2005) first found that deep learning needed to transfer previous knowledge to real situations [20]. Ye Xiaoyun (2006) further proposed that deep learning and shallow learning were not mutually exclusive, but continuous and unified [21]. Based on this, Zhang Hao (2012) listed the five characteristics of deep learning and summarized that they were interrelated as a whole [22]. Later scholars gradually applied deep learning to teaching and used it to guide teaching design. Guo Hua (2016) believed that the occurrence of deep learning required the guidance from teachers and supplement of challenging materials [23]. Cui Yunhuo (2017) set out that deep learning was a process in which students showed high input, high cognitive participation and meaningful engagement in the complex learning environment created by teachers [24].

As is known from above, the early research of deep learning mainly focuses on its definition and characteristics. Although the academic community does not give a unified definition, it can be concluded from the connotations and characteristics that researchers try to convey. Deep learning does not happen naturally, but needs following promoting conditions: First of all, teachers should provide students with elaborately prepared teaching materials with specific teaching objectives. Secondly, the occurrence of deep learning requires pre-designed teaching steps based on teaching objectives. Thirdly, the teaching objectives are problems-solving oriented. Finally, students' transfer and application ability is the 
core ability to be developed in the deep learning process.

\subsection{Deeper Learning Cycle}

As for the teaching steps for deep learning, American scholar Eric Jensen \& LeAnn Nickelsen (2010) showed Deeper Learning Cycle in the book Seven Powerful Strategies for Deep Learning, which provides reference for teaching model (showing in Chart 1) [25]. It contains such teaching procedures as setting teaching objectives, creating learning environment, activating the original knowledge, forming the new knowledge and carrying out deep learning processing, with learning evaluation permeating into previous steps. It is a teaching model, as well as a learning model, which helps learners form critical understanding, complete knowledge acquisition, transfer and application, and develop their problem-solving abilities.

Li Qi and Yang Mei (2017) focused on the theoretical framework of the links of Deeper Learning Cycle [26]. First, they indicated that teaching objectives should be set from the perspective of developing students' higher-level thinking ability. Second, the premise of deep learning is to carry out pre-evaluation, which is necessary to based on a systematic strategy that has been refined through scientific empirical research. Third, learning is the interaction between students and learning environment, which contains such elements as teaching materials to stimulate students' cognitive conflict, cultural background of interpersonal relationship and diversified learning activities. Fourth, the major step of deep learning is to create situations to realize the deep processing of knowledge through meaning construction. Fifth, evaluation is supposed to be based on objectives. These steps construct the process of deep learning. While in a real teaching environment, it needs to be adjusted to meet the characteristics of the course, as well as the real situation of students, aiming to achieve the best teaching effect.

\section{Deep Learning-Based Humanistic Education in College English Teaching}

As Harvard Committee (2015) believed that language should not only be used as a tool, but also a bridge, through which people entered another culture, understanding their ideological and historical developing process, and discovering some deep and vibrant works and ideas [18].

Guided by Deep Learning Theory and based on Deeper Learning Cycle, this

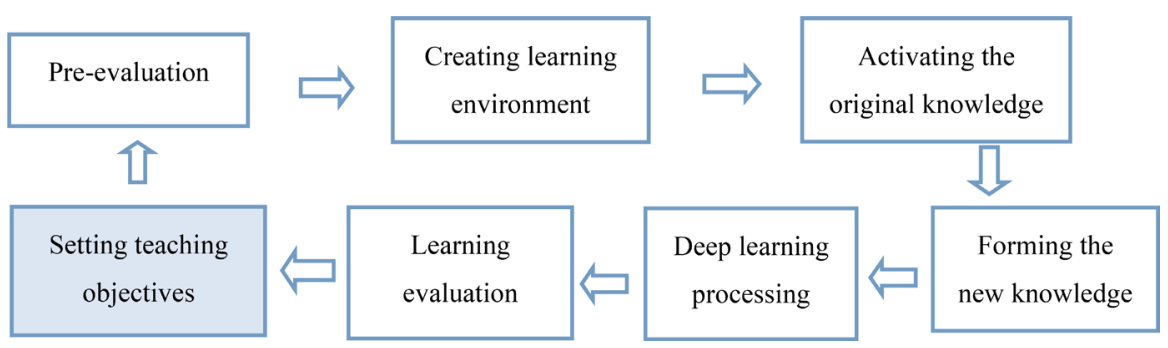

Chart 1. Deeper learning cycle. 
paper constructs a teaching model of humanistic education in college English, which mainly focuses on three major steps: objective setting based on problem solving, element exploration on humanistic education, and deep learning-based integration of humanistic education into language teaching.

\subsection{Problem Solving-Based Objective Setting}

Teaching objectives are the basic guarantee to promote deep learning. American scholars Jonassen.D.H (2000) believed that cultivating students' ability to solve practical problems is of great significance to the development of their high-level thinking ability [27]. Under the concept of project-based learning, American Deep Learning Alliance also insisted on that teaching should be around practical problems and objectives should be set to form products or solve problems (Larmer, J., 2013) [28]. Domestic scholars also regarded problem solving as a sign of deep learning (Liu Zheyu, Wang Zhijun, 2017) [29].

And three principles should be followed in problem solving-based objective setting: first, the problem implies teaching objectives. Students achieve the three-dimensional objectives of knowledge, skill and emotion through the process of solving a problem. Second, the problem has the developing value. According to Vygoski's "proximal development zone" hypothesis, problem setting should accord with students' potential development level. Third, the problem is better to be related to the students' experience, which is conducive to the transformation of the new and previous knowledge.

\subsection{Element Exploration on Humanistic Education}

The prerequisite for occurrence of deep learning is to provide students with challenging content, and to place students in learning environment, which was the sum of teaching materials, cultural background of interpersonal relations and various learning activities, among which teaching materials came first (Guo Hua, 2016 [23]; Li Qi \& Yang Mei, 2017 [26]). Thus, choosing suitable teaching materials which can not only meet students' level but also promote students' high-level thinking ability is an essential condition to trigger deep learning.

The exploration of humanistic elements is mainly through two ways: first of all, excavate the humanistic elements from textbooks. Each unit of a textbook revolves a theme, which covers not only the universal topics of friendship, love, life and death, but also the important concepts of freedom, responsibility, science and religion. Secondly, actively supplement the language training materials containing humanistic elements, for example, the literary works related to unit themes, which can not only arouse students' rational discussion and literary imagination of the theme, but also improve students' language perception and humanistic feelings through classical literature reading.

\subsection{Deep Learning-Based Integration of Humanistic Elements into Language Teaching}

According to Deeper Learning Cycle, the deep processing methods include: 
processing for awareness, processing for analysis and synthesis, processing for application, and processing for assimilation (Eric Jensen \& LeAnn Nickelsen, 2010) [25]. Therefore, the teaching process should be guided by practical problems, using Socrates heuristic questioning method and task-based group discussion to guide students not only to absorb the information, but also to help them understand how the language conveys the information and expresses the ideas, and evaluate every stage of teaching process. Detailed processes are as following:

\section{1) Creating a Humanistic Learning Environment}

Learning is the interaction between students and environment, and the precondition of deep learning is that students are placed in a learning environment, which includes teaching materials, the cultural background of interpersonal relations and various learning activities (Li Qi, Yang Mei, 2017) [26].

College English humanistic learning environment can be set up in combination with characteristics of the curriculum and college students. Firstly, as for college English teaching, language training is an important task. Thus selecting training materials containing humanistic elements to practice listening, speaking, reading, writing and translation is an intangible way of humanistic education. Secondly, contemporary college students are growing up with the development of the network, and basically can be regarded as network aborigines. Therefore, network can be made full use of to create a fully immersed learning environment for humanistic education. For example, use function modules of umooc, such as resources, cloud teaching materials, group tasks, discussion board and so on, as the platform to share the learning humanistic materials, issue learning task lists, and carry out the learning activities. Finally, carry out various extracurricular activities to combine language training with students' interest and humanistic education. Through daily network, teaching platform and extracurricular activities can we create a three-dimensional learning environment for humanistic infiltration.

\section{2) Applying Practical Problems to Lead the Teaching Process}

Knowledge transfer and application is an important evidence for the occurrence of deep learning. It shows not only the learning results, but also the embodiment of learning style. It is also a simulated social practice for students in the process of learning (Guo Hua, 2016) [23]. Therefore, problem consciousness should be beard in mind when supplementing learning materials and organizing learning activities.

Meanwhile, due to longer publication time because of compilation and revision, the textbooks inevitably lag behind or are even outdated in some contents. Starting with realistic issues and supplementing such teaching materials as current news or social issues, can bring fresh corpus to students' study, stimulate their interests and make them obtain novel learning experience.

\section{3) Humanistic Quality Oriented Evaluation System}

Evaluation points to the significance of teaching. At present, most of the courses adopt the combination of formative and summative assessment. How- 
ever, the evaluation of humanistic education is difficult to quantify, as students' psychological growth, literacy promotion and value formation are invisible. Therefore, humanistic learning evaluation should not only exist after the teaching activities, but infiltrate into all steps of teaching activities. And the evaluation subject should not only be teachers, but also include peers and students themselves.

To reform evaluation methods and establish an evaluation system that reflects the humanistic quality is vital. As for the summative assessment, it is necessary to incorporate the contents conducive to the development of students' personality into the examination. And the examination should not be too objective; the standard answers should not be too limited; the examination questions should be as open as possible, leaving room for students to give full play to their subjectivity. Besides, teachers also need to develop new and diversified evaluation models to assess humanistic education. For example, give more portions to the formative assessment on activities like discussion, speech, debate, role-play or thesis writing, which can develop students' language application ability, as well as their English innovation ability, to meet the need of current education for all-around development.

\section{Research Significance}

Permeating humanistic education into language training is vital to college English teaching. College English teaching should not only cultivate language technicians, focusing on such language skill training as listening, speaking, reading, writing and translation, but should cultivate high-quality talents with both professional knowledge and cultural heritage. In addition, this teaching model not only enriches the theoretical basis of humanistic education in language teaching, but is also the application of deep learning theory in language teaching, which provides reference for the design, construction and implementation of humanistic education in language courses.

\section{Conclusion}

The promotion of humanistic education has pointed out a new direction for the innovation of college English teaching. It is an important task to research what effective methods to apply to integrate humanistic elements into learning process, and how to use advanced teaching concept to guide the implementation of humanistic education. The current paper conducts a model of language learning combined with humanistic education in college English course by the steps of problem solving-based objective setting, two-way material exploration on humanistic education, and deep learning-based integration of humanistic elements into language teaching, aiming to bring up students to become ones with profound cultural literacy, noble personality, elegant ambition, and humanistic care for others and the society.

However, the research on integrating humanistic education into college Eng- 
lish teaching should not only be limited to theoretical discussion, but also be supported by more empirical studies. And the implementation of humanistic education in practice is a systematic project, which involves the reconstruction of the university English curriculum system, the scientific setting of the teachers' teaching evaluation system and the student evaluation index system. Due to the limitation of the article length, the author does not discuss these here. Meanwhile, this deep learning-based humanistic teaching model is still in the exploring stage, and more issues such as exploring more steps of Deeper Learning Cycle, evaluation methods and the construction of evaluation system will be the focus of further investigation.

\section{Conflicts of Interest}

The author declares no conflicts of interest regarding the publication of this paper.

\section{References}

[1] Zhang, Z. (2003) On Utilitarianism and Humanism in Foreign Language Education. Foreign Language Teaching and Research, 6, 453-457.

[2] Liu, Y. (2000) Reflections on the Setting of Foreign Language Specialty in Colleges and Universities. Foreign Language World, 3, 12-17.

[3] Liu, X. (2013) On the Cultivation of Speculative Ability in College English Teaching. Foreign Language World, 5, 59-66.

[4] Ren, X. (2009) On Humanistic Education in Foreign Language Teaching. Heilongjiang Researches on Higher Education, 8, 190-192.

[5] Hu, W. and Sun, Z. (2006) Highlighting the Characteristics of Subject and Strengthening Humanistic Education-On the Current Reform of English Major Teaching. Foreign Language Teaching and Research, 5, 243-247+319.

[6] Luo, H. (2008) The Strategy of Implementing Humanistic Education in College English Course. Education Research Monthly, 12, 32-33.

[7] Yue, H. (2010) Thoughts on Humanistic Spirit of Students in College English Teaching. Career and Education, 33, 183-184.

[8] Su, L. (2018) The Synthesis of Language Study and Liberal Education in English Teaching. Foreign Language Learning Theory and Practice, 2, 65-70+65.

[9] Zhang, M. (2008) On Humanistic Education: the Meanings, Values and Characteristics. Journal of Shanxi Normal University (Social Science Edition), 4, 130-134.

[10] Cai, J. (2017) On Instrumentality and Renew of Foreign Language Teaching From the Perspective of Language Properties. Journal of Northeast Normal University (Philosophy and Social Science), 2, 1-6.

[11] Sun, Y. (2015) Training of Foreign Language Education and Speculative Ability. Foreign Languages in China, 2, 1+23.

[12] Department of Higher Education (2020) College English Curriculum Requirements. https://www.renrendoc.com/paper/115871275.html

[13] Marton, F. and Saljo, R. (1976) On Qualitative Differences in Learning: I-Outcome and Process. British Journal of Educational Psychology, 1, 7-8.

[14] Ramsden, P. (1988) Context and Strategy: Situational Influences on Learning. 
Learning Strategies and Learning Styles, 3, 159-184.

[15] Evans, B. and Honour, L. (1997) Getting inside Knowledge: The Application of Entwistle's Model of Surface/Deep Processing in Producing Open Learning Materials. Educational Psychology, 2, 127-139. https://doi.org/10.1080/0144341970170109

[16] Biggs, J.B. and Collins, K.F. (1982) Evaluation the Quality of Learning: The SOLO Taxonomy. Academic Press, New York. https://doi.org/10.1016/C2013-0-10375-3

[17] Huberman, M., Bitter, C., Anthony, J. and O'Day, J. (2014) The Shape of Deeper Learning: Strategies, Structures, and Cultures in Deeper Learning Network High Schools. American Institutes for Research, Washington DC.

[18] Johnson, L., Adams Becker, S., Estrada, V. and Freeman, A. (2015) NMC Horizon Report. 2015 K-12 Edition, the New Media Consortium, Austin.

[19] Wiggins, G. and McTighe, J. (1998) Understanding by Design. ASCD, Alexandria.

[20] He, L. and Li, J. (2005) Promoting Students' Deep Learning. Computer Teaching and Learning, 5, 29-30.

[21] Ye, X. and Qin, J. (2006) On Surface Learning and Deep Learning. Software Guide, 2, 19-21.

[22] Zhang, H., Wu, X. and Wang, J. (2014) Deep Learning Objective and Evaluation System Construction. China Educational Technology, 7, 51-55.

[23] Guo, H. (2016) The Deep Learning and Its Significance. Course-Material-Method, 11, 25-32.

[24] Cui, Y. (2017) Educational Background to Deep Learning. People's Education, 20, $43-48$.

[25] Jensen, E. and Nickelsen, L. (2010) Seven Powerful Strategies for Deep Learning. Wun, N., Trans., East China Normal University Press, Shanghai, 11.

[26] Li, Q. and Yang, M. (2107) Practice and Research on Deep Learning of Basic Computer Course based on DELC. China Educational Technology Equipment, 6, 78-80+86.

[27] Jonassen, D.H. (2000) Toward a Design Theory of Problem Solving. Educational Technology Research and Development, 4, 63-85.

[28] Larmer, J., Mergendoller, J.R. and Boss, S. (2013) PBL for 21st Century Success: Teaching Critical Thinking, Collaboration, Communication, and Creativity. Buck Institute for Education, Novato, 5-6.

[29] Liu, Z. and Wang, Z. (2017) The Empirical Study of Behavior Engagement Influence on Deep Learning: Exemplified with Video Learning in Virtual Reality (VR) Environment. Journal of Distance Education, 1, 72-81. 